\title{
DESENVOLVIMENTO DO FEIJÃO-FAVA (Phaseulus lunatus L.) SOB DÉFICIT HÍDRICO CULTIVADO EM AMBIENTE PROTEGIDO
}

\author{
A. E. S. OLIVEIRA ${ }^{1}$, M. SIMEÃO ${ }^{2}$, F. E. P. MOUSINHO ${ }^{3}$ e R. L. F. GOMES \\ Universidade Federal do Piauí - UFPI \\ aeudesousa@hotmail.com¹, marcelosimeao16@gmail.com², fepmousi@ufpi.edu.br ${ }^{3}$,rlfgomes@ufpi.edu.br ${ }^{4}$
}

Artigo submetido em dezembro/2013 e aceito em fevereiro/2014

\section{RESUMO}

O presente trabalho teve por objetivo avaliar os efeitos do déficit hídrico sobre o desenvolvimento do feijãofava em ambiente protegido. $O$ experimento foi conduzido em vasos sob casa de vegetação, com cobertura de polietileno de baixa densidade de $15 \mu \mathrm{m}$ de espessura, na área experimental do Colégio Agrícola de Teresina da Universidade Federal do Piauí (UFPI), Teresina-PI, Brasil. O delineamento experimental foi inteiramente casualizado (DIC) e os tratamentos consistiram da combinação de indução do estresse hídrico de $50 \%$ da evapotranspiração do feijão-fava, sendo estes: estresse hídrico na fase vegetativa l; estresse hídrico na fase vegetativa II; estresse hídrico na fase reprodutiva III;Estresse hídrico na fase reprodutiva
IV; estresse hídrico nas fases vegetativa I e II; Estresse hídrico nas fase vegetativa e reprodutiva II, III e IV; estresse hídrico nas fases reprodutiva III e IV; estresse hídrico na fases vegetativa e reprodutiva I, II e III; estresse hídrico nas fases vegetativa e reprodutiva I, II, III e IV e um tratamento sem estresse hídrico. Foram avaliadas, índice de área foliar, teor de clorofila e abortamento de flores e vagens. $O$ déficit hídrico afetou o desenvolvimento do feijão-fava, diminuindo o índice de área foliar, índice de clorofila, e aumentando o abortamento de flores e vagens. O feijão-fava foi mais sensível ao estresse hídrico quando o mesmo deu-se em mais de uma fase de desenvolvimento.

PALAVRAS-CHAVE: Estresse Hídrico, Irrigação, Cultivo Protegido.

\section{DEVELOPMENT OF FAVA BEANS (Phaseolus lunatus L.) GROWN UNDER WATER DEFICIT IN GREENHOUSE}

\begin{abstract}
This study aimed to evaluate the effects of water deficit on the development of fava bean in greenhouse. The experiment was conducted in pots in a greenhouse covered with low density polyethylene $15 \mathrm{~mm}$ thick, in the experimental area of Teresina Agricultural College of the Federal University of Piauí (UFPI), Teresina-PI, Brazil. The experimental design was completely randomized and the treatments consisted of the combination of induced water stress $50 \%$ of the evapotranspiration of fava beans, which are: water stress at vegetative stage I; drought stress at vegetative stage II water stress on reproductive phase III water stress during the reproductive phase IV, water stress in vegetative stages I
\end{abstract}

and II water stress in vegetative and reproductive phases II, III and IV; drought stress during the reproductive III and IV, water stress on vegetative and reproductive stages I, II and III water stress on vegetative and reproductive stages I, II, III and IV treatment without water stress. It was evaluated leaf area index, chlorophyll content and abortion of flowers and pods. The drought has affected development, reducing the leaf area index, chlorophyll content, and increasing the abortion of flowers and pods. The fava bean was more sensitive to water stress when it came in more than one phase of development.

KEYWORDS: Water Stress, Irrigation, Greenhouse. 


\section{INTRODUÇÃO}

O feijão-fava (Phaseolus lunatus L.), uma das cinco espécies cultivadas do gênero Phaseolus, é uma leguminosa tropical caracterizada por elevada diversidade genética e elevado potencial de produção, que se adaptam às mais diferentes condições ambientais, mas desenvolve-se melhor nos trópicos úmidos e quentes (Maquet et al., 1999), sendo amplamente distribuída pelas Américas (Gutíerrez-Salgado et al.,1995). Segundo Vieira (1992), o feijão-fava adapta-se melhor em solo areno-argiloso, fértil e bem drenado, tendo bom rendimento com $\mathrm{pH}$ entre 5,6 e 6,8, mas tolera as mais diversas condições ambientais, sendo considerado mais tolerante à seca que o feijão-comum.

É uma espécie plurianual, predominantemente autógama, com aproximadamente $10 \%$ de taxa de cruzamento natural (Hardy et al., 1997). De acordo com Beyra e Artiles (2004), o hábito de crescimento dessa espécie pode ser indeterminado trepador, com o desenvolvimento da gema terminal em uma guia, ou determinado anão com desenvolvimento completo da gema terminal em uma inflorescência. O feijão-fava se destaca como uma das culturas da região Nordeste do Brasil, cultivado em regime de sequeiro, com pouco uso de tecnologias, por agricultores familiares, resultando em baixos índices de produtividade, e grande oscilação na produção. A sensibilidade do feijão-fava ao déficit hídrico no solo e as incertezas climáticas, principalmente as relacionadas às variações pluviométricas entre anos e locais de cultivo determinam esses baixos índices de rendimento e oscilação da produção anual desta cultura. 0 objetivo do presente trabalho foi estudar o desenvolvimento do feijão-fava sob o estresse hídrico avaliando a variação no teor de clorofila, abortamento de flores e vagens e índice de área foliar.

\section{MATERIAIS E MÉTODOS}

O experimento foi conduzido em casa de vegetação, com cobertura de polietileno de baixa densidade, de $15 \mu \mathrm{m}$ de espessura, na área experimental do Colégio Agrícola de Teresina da Universidade Federal do Piauí (UFPI), no município de Teresina-PI, nas coordenadas 0505'21"de latitude sul e 4248'07" de longitude oeste e altitude $74 \mathrm{~m}$. O clima da região, de acordo com a classificação climática de Thornthwaite \& Mather (1955) é C1sA'a', caracterizado como subúmido seco, megatérmico, com excedente hídrico moderado no verão e uma concentração de $32,2 \%$ da evapotranspiração potencial no trimestre setembro - outubro novembro, com precipitação pluvial média anual de $1500 \mathrm{~mm}$, concentrando-se entre os meses de janeiro a maio, temperatura média de $27^{\circ} \mathrm{C}$ e umidade relativa média do ar de $74 \%$ (Andrade Júnior et al., 2005).

O cultivo foi feito em vasos, com solo classificado como ARGISSOLO VERMELHOAMARELO, Distrófico, textura franco-arenosa; muito profundo, ácido, com relevo plano (EMBRAPA, 1999), coletado na camada de 0 a $30 \mathrm{~cm}$, sendo também retiradas amostras para sua caracterização físico-química (Tabela 1). Para a padronização do enchimento dos vasos, de forma a se obter um solo com a mesma densidade do campo foi determinada a densidade pelo método do anel volumétrico e sua umidade. Assim determinou-se a massa do solo a ser colocado em cada vaso considerando que o mesmo tem um volume de oito litros. 
Tabela 1. Caracterização físico-química do solo usado no experimento, Teresina-PI, Brasil, 2012.

\begin{tabular}{|c|c|c|c|c|c|c|c|c|c|c|c|c|}
\hline Camada & $\mathrm{pH}$ & $\mathrm{MO}$ & $\mathrm{P}$ & $\mathrm{K}$ & $\mathrm{Ca}$ & $\mathrm{Mg}$ & $\mathrm{Na}$ & $\mathrm{Al}$ & $\mathrm{H}+\mathrm{A}$ & $S$ & CTC & $\mathrm{V}$ \\
\hline $\mathrm{Cm}$ & $\mathrm{H}_{2} \mathrm{O}$ & g.kg-1 & \multicolumn{2}{|c|}{$--m g d^{-3}--$} & \multicolumn{7}{|c|}{ 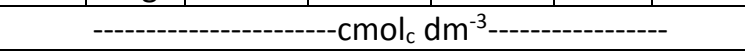 } & $\%$ \\
\hline $0-10$ & 5,3 & 6,8 & 8,5 & 0,14 & 2,1 & 0,8 & 0,03 & 0,04 & 1,5 & 3,1 & 4,5 & 66,5 \\
\hline $10-20$ & 5,4 & 2,6 & 10,0 & 0,10 & 1,7 & 0,5 & 0,03 & 0,00 & 1,4 & 2,3 & 3,7 & 62,4 \\
\hline
\end{tabular}

Foram utilizadas sementes de feijão-fava com hábito de crescimento determinado, porte semi-ereto tipo "moita" e de maturação uniforme, oriunda do banco de germoplasma da UFPI. A adubação de fundação foi realizada nos vasos, utilizando-se o adubo misto NPK (5-30-15) de forma a aplicar $10 \mathrm{~kg}$ de $\mathrm{N}, 60 \mathrm{~kg}$ de $\mathrm{P}_{2} \mathrm{O}_{5}$ e $30 \mathrm{~kg}$ de $\mathrm{k}_{2} \mathrm{O}$ ha-1. O plantio foi feito no dia 10 de marco de 2012, com a semeadura de quatro sementes por vasos. Dez dias após a emergência fezse o desbaste deixando duas plantas por vasos. Aos 20 dias após a emergência fez-se uma adubação de cobertura com aplicação de $40 \mathrm{~kg}$ de $\mathrm{N}$ e $100 \mathrm{~kg}$ de $\mathrm{K}_{2} \mathrm{O} \mathrm{ha}^{-1}$. Durante a condução do experimento, foi realizado controle fitossanitário com aplicação do fungicida a base de metalaxyl$m+$ mancozeb, aos 10 dias após a emergência.

A colheita foi feita quando as vagens se aparentavam em maturação de campo. Foram feitas colheitas a cada semana com o inicio aos 80 dias após a emergência. Após a colheita, as vagens eram acondicionadas em sacos de papel e em seguida contadas e pesadas. Após o termino da colheita aos 120 DAE.

Para a determinação da evaporação e evapotranspiração da cultura foram utilizados doze lisímetros de drenagem construidos com vasos plásticos com capacidade de 8 litros, os quais foram perfurados na base e neste orifício ajustou-se uma mangueira de condução com $10 \mathrm{~cm}$ de comprimento e uma polegada de diâmetro interno, conectando-a a um recipiente plástico com capacidade de 0,5 litros para controle e coleta da água de drenagem.

No fundo de cada vaso colocou-se uma manta geotextil não tecida (Bidim OP 30), para evitar a perda de solo durante a drenagem. Logo acima deste foi colocado uma camada de $3 \mathrm{~cm}$ de brita e outra cobertura de manta geotextil para facilitar a drenagem da água. Em seguida, todos vasos foram preenchidos com solo. Quatro lisimetros foram plantados com feijão-fava para determinar a evapotranspiração da cultura e quatro ficaram somente com solo para determinar a evaporação do solo sem cultivo. A determinação da evaporação e evapotranspiração da cultura do feijão-fava foram determinadas pelo método de lisimetria, que consiste no balanço hídrico, sendo fundamentada na lei da conservação das massas, apresentada por Reichardt (1985) equação (01):

$$
P+I-D-E= \pm h
$$

Em que:

P: precipitação natural, em $\mathrm{mm}$

I: lâmina de irrigação, em $\mathrm{mm}$

D: lâmina de drenagem, em $\mathrm{mm}$

E:evaporação ou evapotranspiração da cultura, em $\mathrm{mm}$

h: variação da armazenagem da água no solo dentro dos lisímetros, em mm.

Considerando que a aplicação da lâmina de irrigação sempre elevava a umidade em todos os lisimetros a capacidade, de campo, a variação no armazenamento e igual a zero, como 
também em virtude da cobertura plástica da casa de vegetação a precipitação pluvial foi desconsiderada. Assim a equação para o calculo da evaporação e evapotranspiração da cultura ficou reduzida à seguinte expressão (02).

$$
E=I-D
$$

O volume de água da evaporação e evapotranspiração da cultura, respectivamente, foram determinadas diariamente em cada vaso, sendo obtido pelo volume aplicado em cada vaso menos o respectivo volume drenado no dia seguinte. Para a transformação dos volumes da evaporação, evapotranspiração de referencia e evapotranspiração da cultura obtidos em cada vaso para valores de lâmina fez-se a divisão destes pela área média dos vasos. A irrigação fora feita diariamente com lâmina correspondente a $100 \%$ da evapotranspiração da cultura, nos tratamentos sem estresse hídrico, enquanto que nos tratamentos sob estresse hídrico a irrigação foi feita com lâmina correspondente a $50 \%$ da evapotranspiração. Os tratamentos consistiram da combinação de indução do estresse hídrico de $50 \%$ da evapotranspiração do feijão-fava, por fases de desenvolvimento da cultura (Figura 3). O ciclo da cultura do feijão- fava foi dividido em quatro fases (I, II, III, IV), sendo: fase I, da emergência aos 20 dias após a emergência (DAE); fase II, dos 20 a 40 DAE; fase III, 40 a 60 DAE e fase IV, 60 a 100 DAE. Foram dez tratamentos com quatro repetições (vaso) no delineamento inteiramente casualizado (DIC) constituindo assim, 40 parcelas, sendo cada, um vaso com duas plantas. Os tratamentos foram: Tratamento 1: Estresse hídrico na fase vegetativa (I); Tratamento 2: Estresse hídrico na fase vegetativa (II); Tratamento 3: Estresse hídrico na fase reprodutiva (III); Tratamento 4: Estresse hídrico na fase reprodutiva IV); Tratamento 5: Estresse hídrico nas fases vegetativa (I e II); Tratamento 6: Estresse hídrico nas fase vegetativa e reprodutiva (II, III e IV); Tratamento 7: Estresse hídrico nas fases reprodutiva (III e IV); Tratamento 8: Estresse hídrico na fases vegetativa e reprodutiva (I, II e III); Tratamento 9: Estresse hídrico nas fases vegetativa e reprodutiva (I, II, III e IV) e Tratamento 10: Irrigação Plena. Para a análise estatística usou-se o software ASSISTAT Versão 7.6 beta (Silva et. al., 2009). Para interpretação dos resultados, utilizou-se a análise da variância, aplicando-se o teste de "F" e quando significativo, aplicou-se o teste de Tukey para ranquear as médias dos tratamentos. Para o calculo do teor de clorofila usou-se o medidor portátil de clorofila, clorofiLOG, que permite leituras instantâneas do teor relativo de clorofila na folha sem, no entanto, destruí-la (Falker, 2008).

A área foliar (AF) foi determinado usando o método das dimensões lineares, proposto por Oliveira (1977), Segundo o qual, a área foliar AF, em plantas do feijoeiro, pode ser estimado pela multiplicação das mediadas do comprimento e da largura dos folíolos multiplicado por um fator de correção equação (03):

$$
A F=K\left(C^{*} L\right)
$$

Sendo:

$\mathrm{K}=0,703$ (fator de correção);

$\mathrm{C}=$ Comprimento do folíolo;

$\mathrm{L}=$ largura máxima do folíolo. 
O índice de área foliar (IAF) de cada tratamento, foi obtido pela relação entre a área foliar (AF) e a área de solo amostrado ( $\triangle \mathrm{S}$ ) equação (04).

$$
\mathrm{IAF}=\mathrm{AF} / \Delta \mathrm{S}
$$

\section{RESULTADOS E DISCUSSÕES}

A emergência das plântulas do feijão-fava ocorreu em média aos oito dias após a semeadura. Nesta fase todos os tratamentos receberam lâmina equivalente a evapotranspiração não sendo submetidas ao déficit hídrico. Não houve diferença significativa entre os tratamentos avaliados quanto ao início da floração das plantas, o qual ocorreu em média aos 36 DAE. Embora não tenha ocorrido diferença significativa entre os tratamentos, aqueles sob estresse hídrico somente na fase vegetativa (I) e somente na fase (II) floresceram aos $34 \mathrm{DAE}$, enquanto que o tratamento com irrigação plena floresceu aos 37 dias e o tratamento com estresse hídrico nas fases II, III e IV o florescimento ocorreu aos 40 dias indicando uma pequena indução de precocidade em função do estresse hídrico na fase vegetativa (Tabela 2). O tempo para inicio da floração também é uma característica da variedade, Santos et. al. (2002) observaram diferenças de até 20 dias para início do florescimento de feijão-fava entre 8 variedades estudadas, sendo que as mais precoces iniciaram a floração aos 49 dias, e as mais tardias aos 71 dias após a semeadura. Silva Neto (2010) estudando 70 acessos de fava constatou que o tempo médio de floração foi de 65 dias, com amplitude de 59 dias. Neste mesmo estudo este autor observou que os genótipos mais precoces atingiram a plena floração aos 39 dias, enquanto o mais tardio aos 98 dias após a emergência.

Tabela 2. Valores do período de duração, em dias após a emergência (DAE), para florescimento, para a maturação de vagens; ciclo da cultura sob estresse hídrico e em irrigação plena.

\begin{tabular}{l|c|c|c}
\hline \multirow{2}{*}{\multicolumn{1}{c|}{ TRATAMENTOS }} & Floração & Maturação & Ciclo \\
\cline { 2 - 4 } & DAE & DAE & DAE \\
\hline E. H. na fase (I) & $34 \mathrm{a}$ & $70,00 \mathrm{a}$ & $120,00 \mathrm{a}$ \\
\hline E. H. na fase (II) & $34 \mathrm{a}$ & $70,00 \mathrm{a}$ & $120,00 \mathrm{a}$ \\
\hline E. H. na fase (III) & $37 \mathrm{a}$ & $76,00 \mathrm{a}$ & $120,00 \mathrm{a}$ \\
\hline E. H. na fase (IV) & $36 \mathrm{a}$ & $72,00 \mathrm{a}$ & $115,00 \mathrm{a}$ \\
\hline E. H. nas fases (I e II) & $36 \mathrm{a}$ & $76,00 \mathrm{a}$ & $120,00 \mathrm{a}$ \\
\hline E. H. nas fase (II, III e IV) & $40 \mathrm{a}$ & $76,00 \mathrm{a}$ & $120,00 \mathrm{a}$ \\
\hline E. H. nas fases (III e IV) & $35 \mathrm{a}$ & $72,00 \mathrm{a}$ & $112,50 \mathrm{a}$ \\
\hline E. H. na fases (I, II e III) & $35 \mathrm{a}$ & $72,00 \mathrm{a}$ & $119,50 \mathrm{a}$ \\
\hline E. H. nas fases (I, II, III e IV) & $37 \mathrm{a}$ & $74,00 \mathrm{a}$ & $111,25 \mathrm{a}$ \\
\hline Com irrigação plena & $37 \mathrm{a}$ & $76,00 \mathrm{a}$ & $115,00 \mathrm{a}$ \\
\hline & $\mathrm{CV}=9,25 \%$ & $\mathrm{CV}=4,97 \%$ & $\mathrm{CV}=3,47 \%$ \\
\hline & $\mathrm{MG}=36,00$ & $\mathrm{MG}=73,4$ & $\mathrm{MG}=117,32$ \\
\hline
\end{tabular}

* Médias seguidas da mesma letra, não diferem entre si, pelo teste de Tukey em nível de 0,05 de probabilidade.

Em relação ao início da maturação das vagens verificou-se através da análise de variância que não houve diferença significativa entre os tratamentos, o início da maturação das vagens deu-se aos 74 DAE (Tabela 2). Nos tratamentos E. H. na fase (I), E. H. na fase (II), E. H. na fase (I, II 
e III) o inicio da maturação deu-se aos 70, 70 e 72 dias após a emergência respectivamente, enquanto que no tratamento, com irrigação plena o inicio da maturação deu-se aos 76 DAE e nos demais tratamentos; E. H. nas fase (II, III e IV); E. H. nas fases (I e II) e E. H. na fase (III) aos 76 DAE. A maturação do feijão-fava ocorreu de forma desuniforme, e mesmo na fase de maturação, alguns ramos continuavam a emitir inflorescência, principalmente nos tratamentos que durante a fase de maturação estavam recebendo a lamina de água requerida pela cultura.

Quanto a analise de variância para ciclo da cultura em (DAE) não houve diferença significativa pelo teste de $F$, sendo que o ciclo da cultura foi em media de 117 dias. Os tratamentos, E. H. na fase (I), E. H. na fase (II), E. H. na fase (III) apresentaram ciclo de 120 DAE, mostrando que após um período de déficit hídrico com retorno da irrigação plena as plantas tiveram um período vegetativo maior, pois nos tratamentos com irrigação plena, $E$. $H$. na fase (IV), E. H. nas fases (III e IV) e E. H. nas fases (I, II, III e IV) apresentaram ciclo de 115, 115, 112 e 111 DAE, respectivamente. Oliveira et. al., (2010) estudando a fenologia e o desenvolvimento vegetativo do feijão-fava a fase de maturação dos frutos iniciou-se entre 51 e 74 dias, a maturidade de $50 \%$ das vagens entre 67 e 85 dias e a maturação completa ocorreu entre 84 e 97 dia, quanto ao ciclo, sob condições de casa de vegetação, os acessos testados apresentaram ciclo de 120 dias, sendo que a maturação de campo aconteceu entre os 84 e 97 dias.

Houve diferença no IAF, a $5 \%$ pelo teste $F$, para o estresse hídrico nas fases de desenvolvimento do feijão-fava, o menor IAF, foi apresentado, nos tratamentos estresse hídrico na fase vegetativa II, e estresse hídrico nas fases II, III e IV; com IAF de 1,69 e 1,39 respectivamente. No tratamento sem déficit hídrico, com irrigação plena o IAF foi de 3,20 (Tabela 3). A redução da área foliar em plantas sob déficit hídrico pode se traduzir numa estratégia de sobrevivência, com o intuito de diminuir a área disponível à transpiração (Correia e Nogueira, 2004). Tal redução constitui um mecanismo morfológico de defesa, pois a redução da interface entre a planta e a atmosfera reduz a transpiração, o que é positivo, porém também reduz a assimilação fotossintética, o que é negativo para a produção. Com área foliar menor, há diminuição na transpiração, conservando água no solo por período mais longo (Taiz e Zeiger, 2004). De acordo Fernández et al. (1996), o uso da água pelas plantas é determinada pela área foliar e, uma vez exposta ao déficit hídrico esta é diminuída. Segundo Taiz e Zeiger (2004), existe uma estreita relação entre a disponibilidade de água no solo e a área foliar, sendo menor o crescimento foliar com a redução da umidade do solo, sugerindo uma grande sensibilidade desta variável a deficiência hídrica. Houve efeito significativo em nível de $1 \%$ do déficit hídrico sobre índice de abortamento de flores e vagens (Tabela 3).

Tabela 3. Índice de área foliar; índice de abortamento de flores e vagens do feijão-fava, sob estresse hídrico e em irrigação plena.

\begin{tabular}{l|c|c}
\hline \multirow{2}{*}{ TRATAMENTOS } & Índice de Área foliar & Índice Abortamento \\
\cline { 2 - 3 } & & $\%$ \\
\hline E. H. na fase (I) & $2,04 \mathrm{ab}$ & $59,94 \mathrm{ab}$ \\
\hline E. H. na fase (II) & $1,69 \mathrm{~b}$ & $58,34 \mathrm{ab}$ \\
\hline E. H. na fase (III) & $1,90 \mathrm{ab}$ & $61,43 \mathrm{ab}$ \\
\hline E. H. na fase (IV) & $2,19 \mathrm{ab}$ & $59,17 \mathrm{ab}$ \\
\hline E. H. nas fases (I e II) & $2,62 \mathrm{ab}$ & $67,35 \mathrm{a}$ \\
\hline E. H. nas fase (II, III e IV) & $1,39 \mathrm{~b}$ & $62,83 \mathrm{ab}$ \\
\hline E. H. nas fases (III e IV) & $2,63 \mathrm{ab}$ & $64,88 \mathrm{ab}$ \\
\hline
\end{tabular}




\begin{tabular}{l|c|c}
\hline E. H. na fases (I, II e III) & $2,08 \mathrm{ab}$ & $73,05 \mathrm{a}$ \\
\hline E. H. nas fases (I, II, III e IV) & $2,08 \mathrm{ab}$ & $64,68 \mathrm{ab}$ \\
\hline Com irrigação plena & $3,20 \mathrm{a}$ & $27,10 \mathrm{~b}$ \\
\hline & $\mathrm{CV}=26,93 \%$ & $\mathrm{CV}=26,30 \%$ \\
\hline & $\mathrm{MG}=1,76$ & $\mathrm{MG}=59,88$
\end{tabular}

* Médias seguidas da mesma letra, não diferem entre si, pelo teste de Tukey em nível de 0,05 de probabilidade.

O tratamento irrigação plena apresentou índice de abortamento menor do que todos os outros, com taxa de $27,10 \%$. Os demais tratamentos não diferenciaram entre si, apresentando valores de 73,$05 ; 67,35 ; 64,88$ e $62,86 \%$ quando o déficit ocorreu respectivamente na fase I, II e III; I e II; III e IV; II, III e IV. O estresse hídrico durante o período de floração e formação de vagens intensificou o abortamento de flores e vagens de feijão-fava. Resultados semelhantes foram encontrados por Hostalácio e Válio (1984) onde o estresse hídrico durante o período de floração e formação de vagens de feijoeiro induziu o abortamento de flores e vagens jovens, ajudando a formação das primeiras, pois ocorreu uma competição fonte-dreno, sendo então eliminadas flores anormais, com falha na fertilização, ou vagens mais novas que abortam por falta de nitrogênio ou carboidratos. Estresse hídrico na etapa de enchimento de vagens produziu um abortamento de vagens jovens e produção de vagens chochas. A análises de variância, para o índice do teor de clorofila, aos 40,48, 60 e 80 dias após a emergência, na cultura do feijão-fava, em função do estresse hídrico, mostrou que houve efeito significativo do estresse hídrico sobre o teor de clorofila aos 40 e $48 \mathrm{DAE}$, sendo que as plantas que sofreram estresse hídrico na fase III apresentaram menores teores de clorofila, que as plantas não estressadas (Tabela 4).

Tabela 4. Valores médios do índice do teor de clorofila (ICF), medida aos 40, 48, 60 e 80 DAE, em feijão-fava com estresse e sem estresse hídrico por fase de desenvolvimento.

\begin{tabular}{l|c|c|c|c}
\hline \multirow{2}{*}{ TRATAMENTOS } & \multicolumn{4}{c}{ Teor de Clorofila ICF } \\
\cline { 2 - 5 } & $40 \mathrm{DAE}$ & $48 \mathrm{DAE}$ & $60 \mathrm{DAE}$ & $80 \mathrm{DAE}$ \\
\hline E. H. na fase (I) & $33,15 \mathrm{ab}$ & $31,97 \mathrm{~b}$ & $36,25 \mathrm{a}$ & $33,07 \mathrm{a}$ \\
\hline E. H. na fase (II) & $28,00 \mathrm{ab}$ & $29,97 \mathrm{~b}$ & $35,35 \mathrm{a}$ & $33,75 \mathrm{a}$ \\
\hline E. H. na fase (III) & $33,32 \mathrm{ab}$ & $32,97 \mathrm{ab}$ & $35,67 \mathrm{a}$ & $31,55 \mathrm{a}$ \\
\hline E. H. na fase (IV) & $34,77 \mathrm{ab}$ & $35,95 \mathrm{ab}$ & $35,45 \mathrm{a}$ & $33,07 \mathrm{a}$ \\
\hline E. H. nas fases (I e II) & $28,82 \mathrm{~b}$ & $34,80 \mathrm{ab}$ & $33,24 \mathrm{a}$ & $33,25 \mathrm{a}$ \\
\hline E. H. nas fase (II, III e IV) & $32,60 \mathrm{ab}$ & $33,17 \mathrm{ab}$ & $32,80 \mathrm{a}$ & $33,85 \mathrm{a}$ \\
\hline E. H. nas fases (III e IV) & $35,00 \mathrm{ab}$ & $32,60 \mathrm{ab}$ & $31,92 \mathrm{a}$ & $33,07 \mathrm{a}$ \\
\hline E. H. na fases (I, II e III) & $30,17 \mathrm{ab}$ & $30,85 \mathrm{~b}$ & $32,60 \mathrm{a}$ & $31,61 \mathrm{a}$ \\
\hline E. H. nas fases (I, II, III e IV) & $30,22 \mathrm{ab}$ & $32,47 \mathrm{ab}$ & $31,52 \mathrm{a}$ & $29,46 \mathrm{a}$ \\
\hline Com irrigação plena & $39,12 \mathrm{a}$ & $40,47 \mathrm{a}$ & $39,05 \mathrm{a}$ & $35,37 \mathrm{a}$ \\
\hline
\end{tabular}

* Médias seguidas da mesma letra na coluna, não diferem entre si, pelo teste de Tukey em nível de 0,05 de probabilidade.

O estresse hídrico interfere no estado nutricional da planta, diminuiu o ICF, estes resultados diferem dos obtidos por Lima (2008) com a cultura do feijão, que não registrou variações significativas no ICF passíveis de correlação com os efeitos da deficiência hídrica. Aos 60 e 80 DAE (Tabela 4), não houve diferença estatística significativa no teor de clorofila entre os tratamentos. 
O teor de clorofila no tratamento com irrigação plena foi de 39,05 aos 60 DAE e 35,37 aos 80 DAE; no tratamento estresse hídrico nas fases I, II, III e IV o teor de clorofila foi de 31,52 aos 60 DAE e 29,46 aos 80 DAE; no tratamento estresse hídrico na fase I o teor de clorofila foi de 36,25 aos 60 DAE e 33,07 aos 80 DAE, no tratamento estresse hídrico na fase Il o teor de clorofila aos 60 DAE foi de 35,35 e aos 80 DAE foi de 33,75, nos demais tratamentos ocorreu a mesma diminuição do teor de clorofila dos 60 para os 80 DAE. Aos 60 e aos 80 DAE as plantas já estão na fase de maturação das vagens, começando a senescência, com a queda das folhas e diminuição do teor de clorofila em todos os tratamentos.

\section{CONCLUSÕES}

O déficit hídrico afetou o desenvolvimento do feijão fava, diminuiu o índice de área foliar, o teor de clorofila, e aumentou o abortamento de flores e vagens. O feijão-fava foi mais sensível ao estresse hídrico quando o mesmo deu-se em mais de uma fase de desenvolvimento.

\section{REFERÊNCIAS BIBLIOGRÁFICAS}

1. ANDRADE JÚNIOR, A. S.; BASTOS, E. A.; BARROS, A. H. C.; SILVA, C. O.; GOMES, A. A. N. 2005. Classificação climática e regionalização do semi-árido do Estado do Piauí sob cenários pluviométricos distintos. Revista Ciência Agronômica, v. 36 , n. 2, p. 143 - 151.ANDRIOLO, J.L.; POERSCHKE, P.R. Cultivo do Tomateiro em Substratos. Centro de Ciências Rurais Santa Maria, p.12, 1999

2. BEYRA, A.; ARTILES, G. R. 2004. Revisión taxonômica de los gêneros Phaseolus y Vigna (Leguminosae - Papilionoideae) en Cuba. Anales Del Jardín Botánico de Madrid. v.61, n.2, p.135-154.

3. CORREIA, K. G.; NOGUEIRA, R. J. M. C. 2004 Avaliação do crescimento do amendoim (Arachis hypogaea L.) submetido a déficit hídrico. Revista de Biologia e Ciências da Terra, Belo Horizonte, v.4, n.2. Disponível em:< http://eduep.uepb.edu.br/rbct/sumarios/pdf/amendoim deficit.pdf > Acesso em: 19 de abril. 2012

4. EMBRAPA. 1999. Centro Nacional de Pesquisa de Solos (Rio de Janeiro, RJ). Sistema Brasileiro de Classificação de Solos. Brasília: Embrapa Produção da Informação; Rio de Janeiro: Embrapa Solos. 412p

5. FALKER. CFL1030 - clorofiLOG - Medidor eletrônico de teor de clorofila. Disponível em: < http://www.falker.com.br/download.php?file_id=74 >. Acesso em: 19 abril. 2012.

6. FERNÁNDEZ, C. J.; McINNES, K. J.; COTHREN, J. T. 1996. Water status and leaf area production in water-and nitrogen-stressed cotton. Crop Science, Madison, v.36, p.12241233.

7. GUTIÉRREZ-SALGADO A.; GEPTS, P.; DEBOUCK, D.G. 1995. Evidence for two gene pools of the lima bean, Phaseolus lunatus L., in the Americas. Genetic Resources and Crop Evolution, v.42, p.15-28.

8. HARDY, O.; DUBOIS, S.; ZORO BI, I.; BAUDOIN, J.P. 1997. Gene dispersal and its consequences on the genetic structure of wild populations of Lima bean (Phaseolus lunatus) in Costa Rica. Plant Genetic Resources Newsletter, n.109, p.1-6. 
9. HOSTALACIO, S.; VALIO, I.F.M. 1984. Desenvolvimento dos frutos de feijão em diferentes regimes de irrigação. Pesquisa Agropecuária Brasileira, v.19, n.1, p.53-57.

10. LIMA, C. J. G. S. et al. 2008.Modelos matemáticos para estimativa de área foliar de feijão caupí. Revista Caatinga, Mossoró, v. 21, n. 1, p. 120-127.

11. MAQUET, A.; VEKEMANS, X.Z.; BAUDOIN, J.P. 1999. Phylogenetic study on wild allies of lima bean, Phaseolus lunatus L. (Fabaceae), and implications on its origin. Plant Systematics and Evolution, v.218, n.1-2, p.43-54.

12. OLIVEIRA, J. P. 1977. Método não destrutivo para determinação da área foliar do feijoeiro caupi, vigna sinensis (L) savi, cultivado Em casa de vegetação. Ciência Agronômica, v.7, n.12,p.53-57.

13. OLIVEIRA, M. C. P. et al. 2010. Fenologia e desenvolvimento vegetativo. In.: Lopes, A. C. A.; Gomes, R. L. F.; Araujo, A. S. F. A cultura do feijão-fava no meio-norte do Brasil. Teresina : EDUFPI. p.103-115.

14. REICHARDT, K. 1985. Processos de transferência no sistema solo-planta-atmosfera. Campinas. Fundação Cargill. 486p.

15. SANTOS, D.; CORLETT, F. M. F.; MENDES, J. E. M. F.; Wanderley Júnior, J. S. A. 2002. Produtividade e morfologia de vagens e sementes de variedades de fava no Estado da Paraíba. Pesquisa Agropecuária Brasileira, Brasília, DF, v.37, n.10, p.1407-1412. < http://www.scielo.br/pdf/pab/v37n10/13219.pdf> . 10 dez. 2012.

16. SILVA NETO, J. R. 2010. Caracterização morfo-agronômica e avaliação da resistência em acessos de fava ao mosaico dourado e à antracnose. Dissertação (Mestrado em Agronomia) - Universidade Federal de Alagoas, Rio Largo -AL. 93 p.

17. SILVA, F. DE A. S.; AZEVEDO, C. A. V. de. 2009. Principal Components Analysis in the Software Assistat-Statistical Attendance. In: WORLD CONGRESS ON COMPUTERS IN AGRICULTURE, 7, Reno-NV-USA: American Society of Agricultural and Biological Engineers.

18. TAIZ, L.; ZEIGER, E. , 2004. Fisiologia vegetal. 3.ed. Porto Alegre: Artmed. 719 p.

19. THORNTHWAITE, C. W. ; MATHER, J. R. 1955. The water balance. Publications in Climatology. New Jersey: Drexel Institute of Technology. 104 p.

20. VIEIRA, R. F. 1992. A cultura do feijão-fava. Informe Agropecuário, Belo Horizonte, v.16, n.174, p.30 -37. 